\title{
Temperature and Water Level Monitoring System at the Entry of Electronic Engineering Laboratory
}

\author{
Yoice R. Putung \\ Electrical Engeenering Dept \\ Manado State Polytechnic \\ North Sulawesi - Indonesia
}

\author{
Sukandar Sawidin \\ Information Technology Dept \\ Manado State Polytechnic \\ North Sulawesi - Indonesia
}

\author{
Josephin Sundah \\ Electrical Engeenering Dept \\ Manado State Polytechnic \\ North Sulawesi - Indonesia
}

\author{
Ventje F. Aror \\ Electrical Engeenering Dept \\ Manado State Polytechnic \\ North Sulawesi - Indonesia
}

\begin{abstract}
During this Covid-19 pandemic, devices for detecting human body temperature and hand washing water are very important so that we can avoid the spread of Covid-19.

This study aims to make a Body Temperature Monitoring System and Water Level in the form of a prototype. Using the JSN-SR04T (Ultrasonic Distance Waterproof) Sensor to measure the water level and the MILX90614 Sensor (NonContact Temperature Sensor) with the Arduino Uno controller. Information from the height of the water level in the tank and the temperature of the human body can be monitored via the LCD.

The method used is the Prototype Design Method starting at the stage of literature study and data collection. The software and hardware design was continued for the need for measuring the water level and temperature. Next is the stage of making the control system on the prototype, then the testing stage.

The test results If the water level level is High, the water level indicator is Green, the water level is Medium, the water level indicator is Yellow and when the water level is Low the indicator is a Red led light. informs that the water in the tank must be filled.

If the temperature of the human body is $\left\langle 37^{\circ} \mathrm{C}\right.$ LCD display Temperature is normal, but if the temperature $>=37^{\circ} \mathrm{C}$ LCD display Check to a doctor because there is a risk of contracting Covid 19.
\end{abstract}

\section{General Terms}

Body Temperature, Water Level

\section{Keywords}

Arduino Uno, LCD, Sensor JSN-SR04T and MILX90614

\section{INTRODUCTION}

During this Covid-19 pandemic, it is very important for us to take care of our health, especially regarding hand hygiene and body temperature. As is well known, it is an appeal from the government for us to maintain cleanliness and health by washing our hands often, if we leave the house we must wear a mask, keep our distance from other people so as not to transmit the Covid-19 disease.

The problem is, in accessing the information on the Water Level in the tank, it cannot be known because of the lack of quick monitoring whether the water is still there or has run out and body temperature measurements for lecturers and students still use temperature gauges with thermometers that are in direct contact with officers who are held alternately. by officers and may come into contact with other officers who, without us knowing, may already have Covid-19. Based on the problems stated above, we need a system that can monitor body temperature and water level in the hand washing water storage tank, so a design for a Temperature and Water Level Monitoring system will be made at the Entrance of the Laboratory of the Electrical Engineering Department using the Arduino Uno Microcontroller control.

\section{LITERATURE REVIEW}

\subsection{SENSOR JSN-SR04T}

JSN-SR04T (Ultrasonic Distance Waterproof)is an industrial standard ultrasonic module with waterproof capability and high measurement accuracy. JSN-SR04T is a developed version of the ultrasonic module HC-SR04 but with the addition of a waterproof feature.

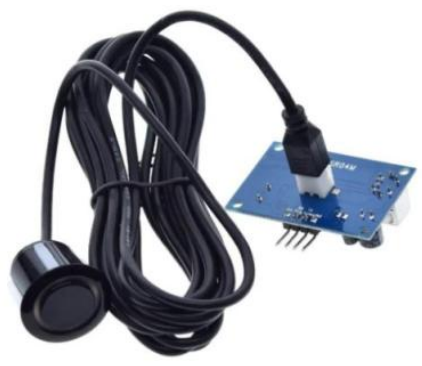

Figure 1. Sensor JSN-SR04T

\subsection{SENSOR MLX90614}

The MLX90614 sensor is a sensor used to measure temperature by utilizing infrared radiation. The MLX90614 sensor is specially designed to detect infrared radiation energy and has been automatically designed so that it can calibrate infrared radiation energy into a temperature scale. The MLX90614 consists of an infrared thermopile detector MLX81101 and signal conditioning ASSP MLX90302 which is used to process the output of the infrared sensor. The thermopile consists of layers or membranes made of silicon and contains a lot of thermocouples so that infrared radiation coming from the object will be captured by the membrane. 


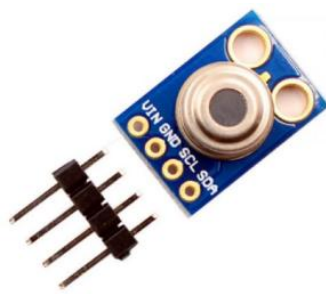

Figure 3. Sensor MLX90614

\subsection{Arduino Uno Microcontroller}

Arduino Uno with ATMega328P has 14 digital inputs/outputs (6 of which can be used for PWM output), 6 analog inputs, $16 \mathrm{MHz}$ clock speed, USB connection, power jack, ICSP header, and reset button. Arduino Uno ATMega328P schematic.

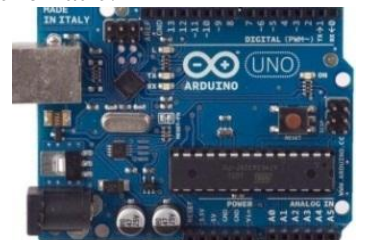

Figure 4. Skema Arduino Uno

\subsection{Liquid Crystal Display(LCD)}

LCD is an electronic circuit that is used to display information or indicators given to the microcontroller. The LCD used is a dot matrix LCD with a character count of $2 \mathrm{x}$ 16. The LCD is very functioning as a viewer which will later be used to display the working status of the tool.

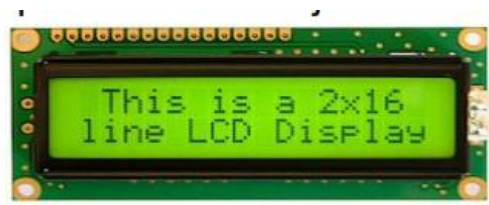

Figure 5. Liquid Cystal Display

\subsection{I2C LCD}

I2C LCD is an LCD module that is controlled serially synchronously with the I2C/IIC (Inter Integrated Circuit) or TWI (Two Wire Interface) protocol. LCD modules are normally controlled in parallel for both the data and control lines. The I2C converter module shown in Figure 5 uses the ICPCF8574 chip from NXP as the controller. This IC is an 8 bit I/O expander for the I2C bus which is basically a shift register.

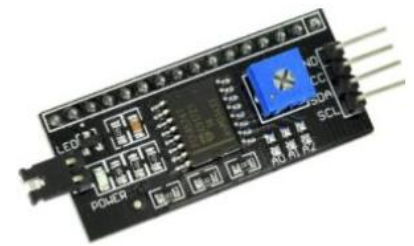

Figure 6. I2C LCD

\section{METHODOLOGY}

In this study, the design method is used which begins with making a block diagram of the system and the design of the Temperature and Water Level Monitoring System. Sensor MLX90624 (Non-Contact Body Temperature Sensor) to detect Human Body Temperature and then processed by the microcontroller the results to be displayed on the LCD.

The designs carried out are: Making block diagrams of control systems, designing power supplies, Relay Drivers for System On/off, JSN-SR04T Sensors, MLX90624 Sensors, Indicator Lights using Arduino Uno microcontroller, Lamp Loads and Monitoring with LCD as well as control system testing integrated to simplify the hardware manufacturing process.

The stages of the research are described as the block diagram in Figure 7. below:

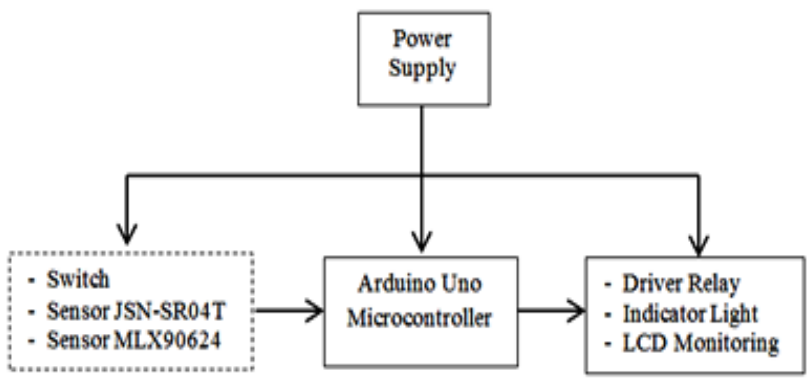

Figure 7. System Block Diagram

Description of block diagram:

1. Designing a power supply for Sensors, Arduino Uno, Relay Drivers and LCD monitoring tools.

2. Designing the ON/OFF Power Supply indicator switch.

3. Designing the JSN-SR04T (Ultrasonic Distance Waterproof) Sensor to detect the Water Level in the tank.

4. Designing Sensor MLX90624 (Non-Contact Body Temperature Sensor) to detect Human Body Temperature.

5. Implementation of the Arduino Uno Microcontroller as a central control system that functions to receive data from sensors, and process the data.

6. Designing LCD (Liquid Crystal Display) and Indicator Lights (Led) for system monitoring.

7. Connecting the Lamp Loads with the control system through the Lamp Driver.

\subsection{Research Model and Design}




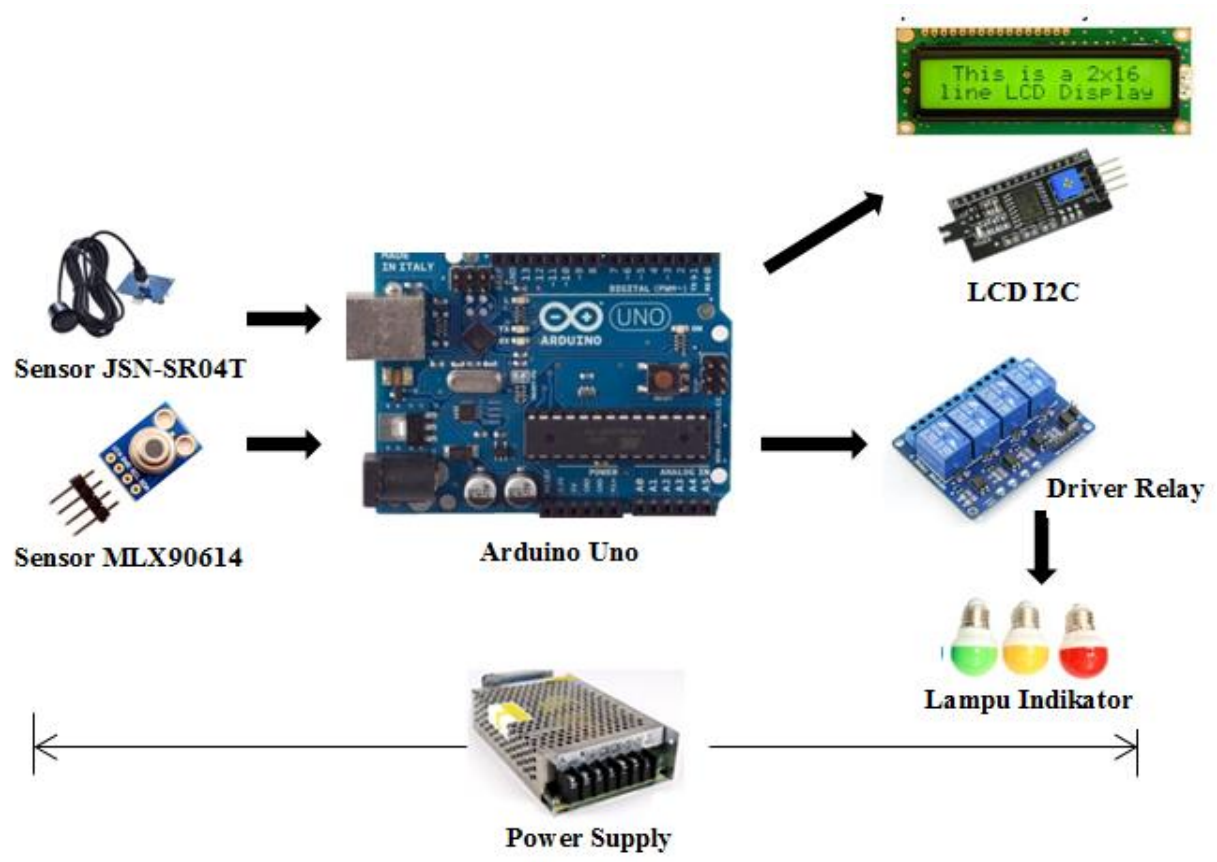

Figure 8. Temperature and Water Level Monitoring System

How the System works:

When the system is activated, the Arduino Uno Microcontroller will detect a signal from the JSN-SR04T (Ultrasonic Distance Waterproof) Sensor to detect the Water Level in the tank and the MLX90614 Sensor to detect human body temperature (Non-Contact Body Temperature Sensor). Next processed Arduino Uno.

If the water level is High, the indicator is Green, the water level is Medium, the indicator is Yelow, and when the water level is Low, the indicator is Red, which informs you that the water in the tank must be filled.

If the temperature of the human body is $<37^{\circ} \mathrm{C}$ LCD display Temperature is normal, but if the temperature $>=37^{\circ} \mathrm{C}$ LCD display Check to a doctor because there is a risk of contracting Covid 19.

\section{FLOW CHART SYSTEM}

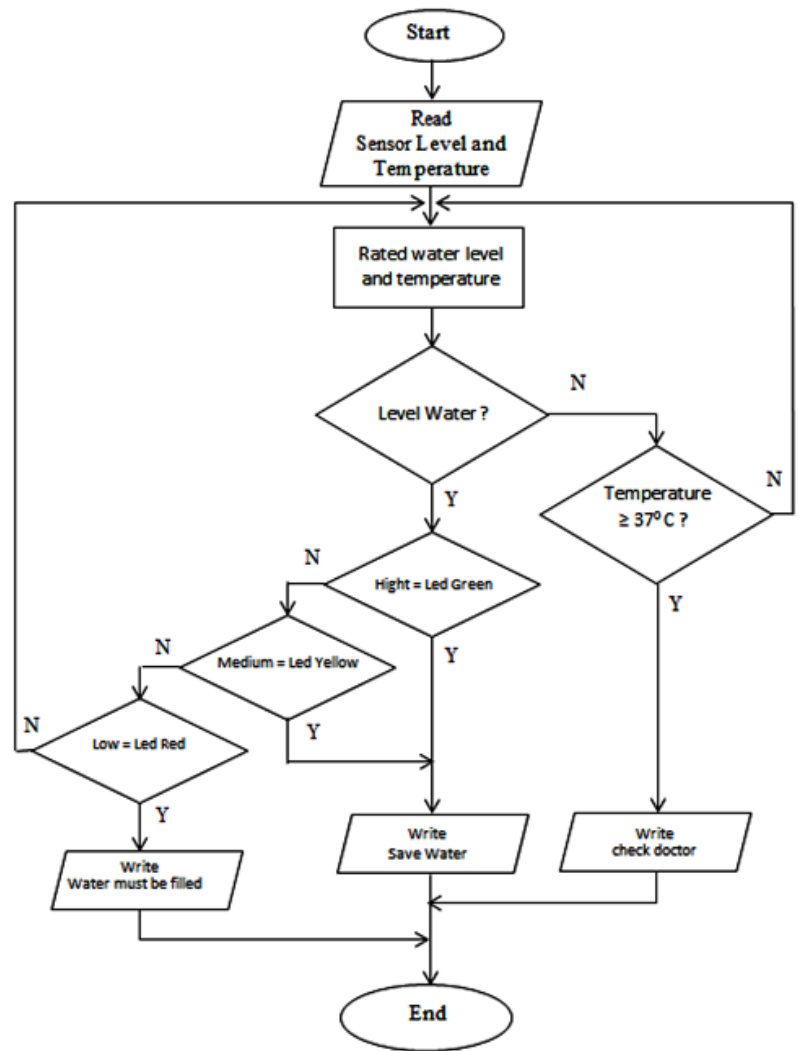

Figure 9. Flow Chart System Temperature and Water Level

System Block Diagram Description:

1. Activate the system

2. Read Sensor Signal Level and temperature.

3. Shows Air Level and Temperature Value.

4. If the water level is high (full) then the green led light is on

5. If the water level is (Medium) then the yellow led light is on, water needs to be added. 
6. If the water level is low, the led light is red, water must be added.

7. If the detected temperature is equal to or greater than $37^{\circ} \mathrm{C}$ then consult a doctor.

\section{RESULTS AND DISCUSSION}

In this section, we will discuss the test steps which include testing the JSN-SR04T (Ultrasonic Distance Waterproof) Sensor circuit, MILX90614 Sensor (Non-Contact Temperature Sensor), Arduino Uno Microcontroller, testing the I2C LCD circuit, testing the relay driver circuit for on/off. indicator led light.

\subsection{Circuit Driver Relay Test}

Testing the relay driver for on/off lamps is carried out to test the magnitude of the input voltage, base current and relay voltage when the circuit is active. Figure 10. shows a test of the relay driver circuit for on/off lamps.

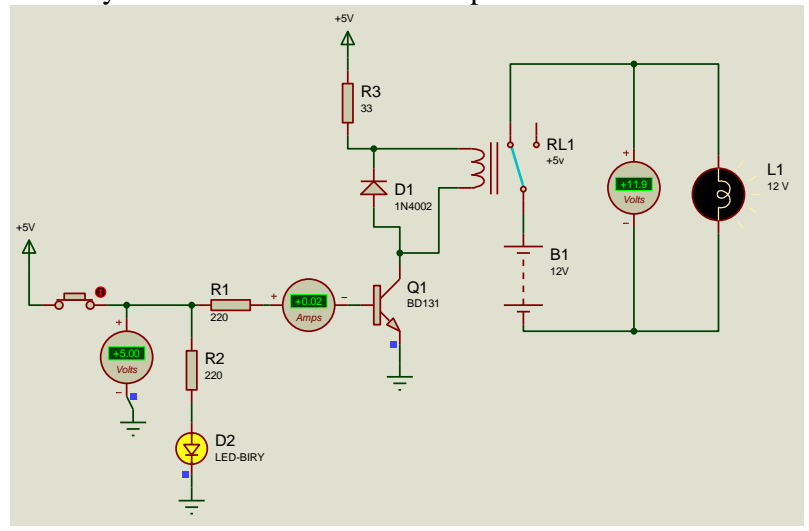

Figure 10. Testing the Indicator Light Driver Circuit

When the push button is pressed, the current will pass through the resistance $\mathrm{R} 1$ and $\mathrm{R} 2$, because the resistance $\mathrm{R} 2$ is installed with a led and connected to neutral, the LED light as an indicator will light up. And the current that passes through R1 will enter through the base of the transistor so that the collector and emitter are connected. The transistor functions as a switch so that the relay works and the DC current can be connected to the $12 \mathrm{Vdc}$ indicator light load and the indicator light is on.

\subsection{LCD Display Test}

LCD testing was carried out using an Arduino Uno microcontroller as a control to run the program displaying characters on the LCD. The program is made using the C language program with Arduino 1.0.6 software.

\author{
Listing of LCD programs as follows: \\ \#include <Wire.h> \\ \#include < Adafruit_MLX90614.h> \\ \#include <LiquidCrystal_I2C.h> \\ Adafruit_MLX90614 mlx = Adafruit_MLX90614(); \\ \#define I2C_ADDR 0x27 \\ LiquidCrystal_I2C lcd(0x27, 16, 2); \\ void $\operatorname{setup}()\{$ \\ lcd.begin(16,2); //initialisasi LCD
}

// initialize the LED pin as an output: pinMode(ledPin, OUTPUT);

// initialize the pushbutton pin as an input:

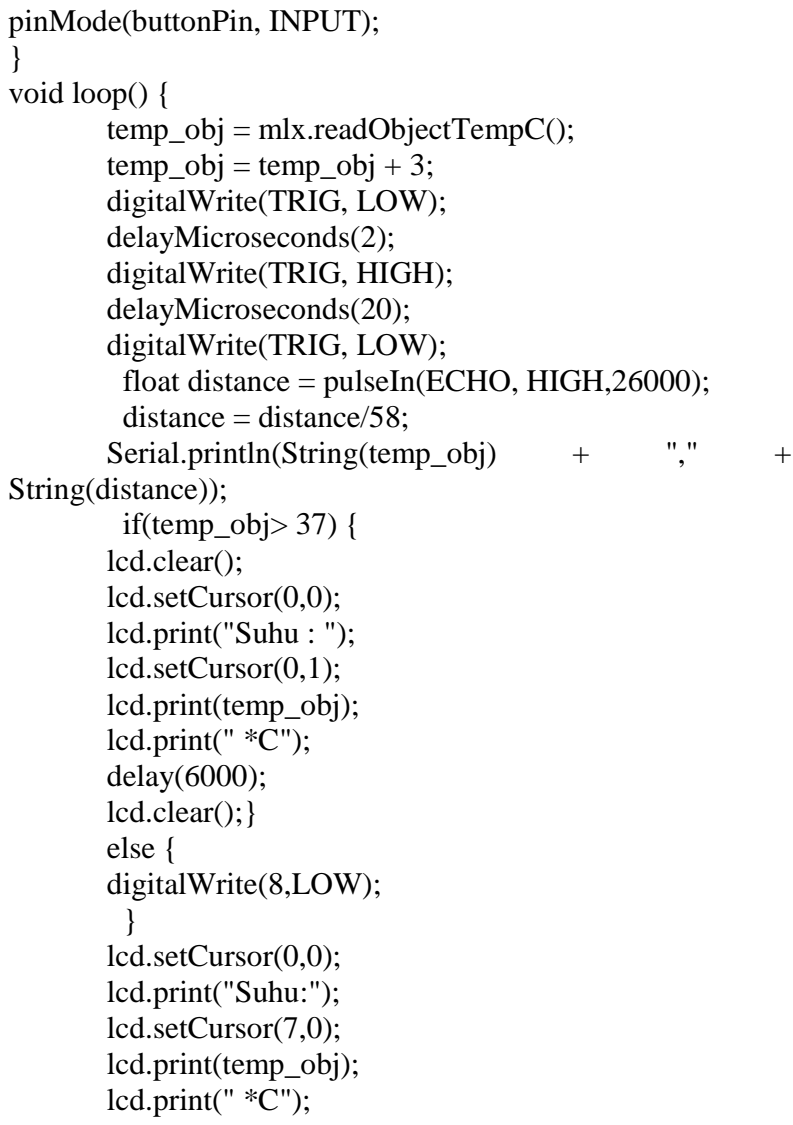

After the program is completed and verified there is no syntax error in the program, the program is uploaded so that it obtains the program used to run the microcontroller. The results of the program on the LCD as shown in Figure 11. Below.

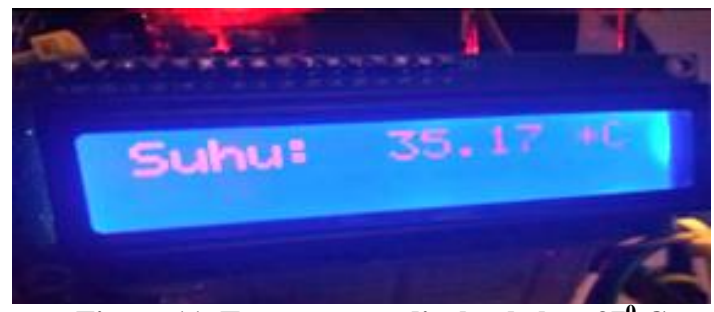

Figure 11. Temperature display below $37^{0} \mathrm{C}$

\subsection{Water Level Test}

Testing the water level in the water reservoir (tank) is carried out using the Arduino Uno microcontroller as a control of the water level to control whether the water is still full, half filled (medium) or low (low) with a LED light indicator. If the distance of the JSN-SR04T level sensor is less than or equal to $25 \mathrm{~cm}$ then the green LED will light up indicating the water is full in the tank. then the red indicator LED lights up. The program is made using the $\mathrm{C}$ language program with Arduino 1.0.6 software.

Listing of Water Level Control program as follows:

if (distance $<=25)\{$

digitalWrite(ledfull,HIGH);

digitalWrite(ledmedium,LOW);

digitalWrite(ledlow,LOW); 
else \{

digitalWrite(ledfull,LOW);

\}

if $($ distance $>=25)\{$

digitalWrite(ledmedium, HIGH);

digitalWrite(ledlow,LOW);

\}

if (distance $>=35)\{$

digitalWrite(ledlow, HIGH);

digitalWrite(ledmedium, LOW);

\}

delay(300);

\}

The results of the program on the water tank as shown in Figure 12 below:

In the picture shows the green indicator LED lights up indicating the water in the tank is still full.

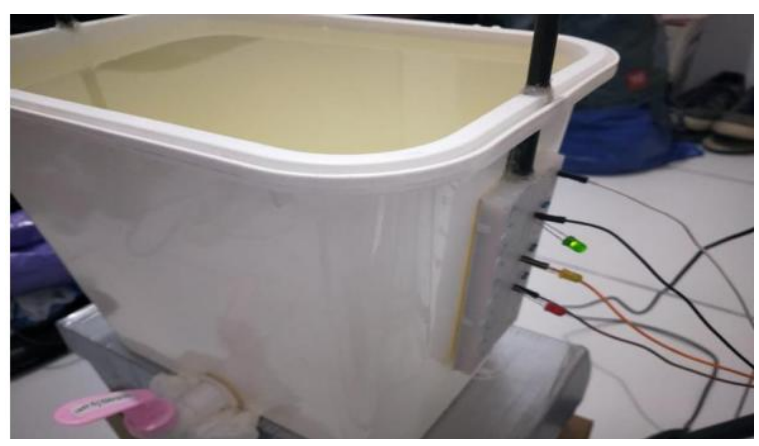

Figure 12. Testing Water Level with Led Indilator

The test is carried out by filling water into the tank as high as $25 \mathrm{~cm}$ from the sensor distance, and reducing the water level by $1 \mathrm{~cm}$ gradually until the sensor distance with the water surface is $35 \mathrm{~cm}$, from the measurement results can be seen in Table 1, that the JSN-SR04T Distance sensor reads the distance from sensor to the water surface.

Table 1. Testing the JSN-SR04T Distance Sensor with Water

\begin{tabular}{|c|l|c|c|}
\hline No. & $\begin{array}{c}\text { Water } \\
\text { Level }\end{array}$ & $\begin{array}{c}\text { Distance } \\
\text { SensorwithWater } \\
\text { (cm) }\end{array}$ & $\begin{array}{c}\text { Indicator } \\
\text { LED } \\
\text { Lights }\end{array}$ \\
\hline 1 & High & 25 & Green \\
\hline 2 & Medium & 26 & Yellow \\
\hline 3 & Medium & 27 & Yellow \\
\hline 4 & Medium & 28 & Yellow \\
\hline 5 & Medium & 29 & Yellow \\
\hline 6 & Medium & 30 & Yellow \\
\hline 7 & Medium & 31 & Yellow \\
\hline 8 & Medium & 32 & Yellow \\
\hline 9 & Medium & 33 & Yellow \\
\hline 10 & Medium & 34 & Yellow \\
\hline 11 & Medium & 35 & Yellow \\
\hline 12 & Medium & 34 & Yellow \\
\hline 13 & Low & 35 & Red \\
\hline
\end{tabular}

\subsection{Monitoring System Test Temperature and Water Level}

Tests are carried out to determine whether the function of each component of the tool is in accordance with the flowchart that has been made, so that improvements can be made to obtain results that are in accordance with the design of both hardware and software.

When the system is activated, the Arduino Uno Microcontroller will detect signals from the JSN-SR04T (Ultrasonic Distance Waterproof) Sensor to detect the Water Level in the tank and the MLX90614 Sensor to detect human body temperature (Non-Contact Body Temperature Sensor). Next processed Arduino Uno,

If the water level Distlevel is High, the water level indicator is Green, the water level is Medium, the water level level is Yellow and when the water level is Low the water level is Red indicating that the water is water. in the tank must be filled.

If the human body temperature $<37^{0} \mathrm{C}$ LCD display Temperature Normal, but if the temperature $>=37^{\circ} \mathrm{C}$ LCD display Check to a doctor because there is a risk of contracting Covid 19.

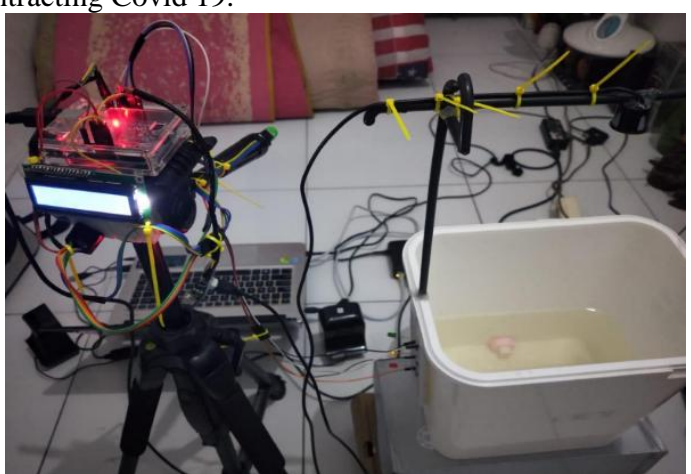

Figure 13. Temperature and Water Level Monitoring System

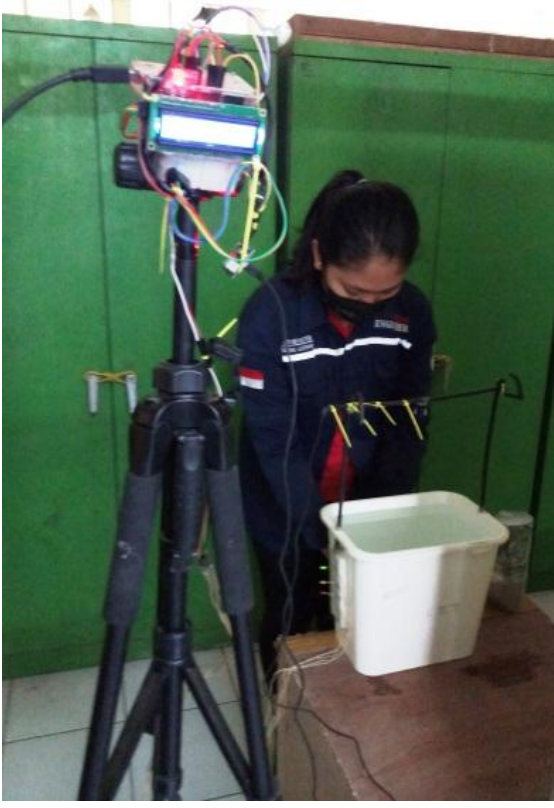

Figure 14. Water Level Test

In figure 14. when students are about to enter the laboratory, they are required to wash their hands or use a hand sanitizer, the Green LED light indicator shows that the water is still full. Then check the body temperature (figure 15) if the body 
temperature is $<37^{\circ} \mathrm{C}$ can enter the laboratory, if the body temperature is $>37^{0} \mathrm{C}$ (figure 16) then students are not allowed to enter the laboratory and on the LCD display: Immediately Check self to a doctor. (Figure 17).

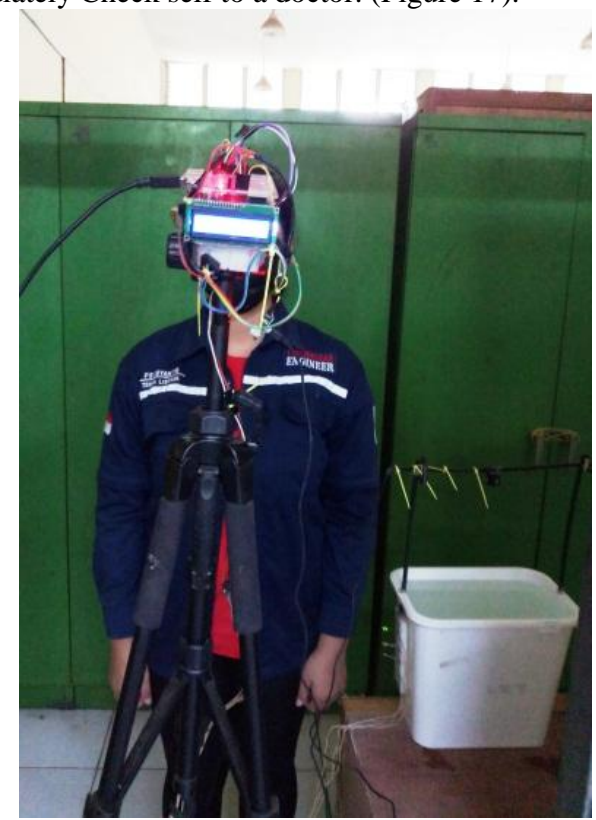

Figure 15. Body Temperature Detection

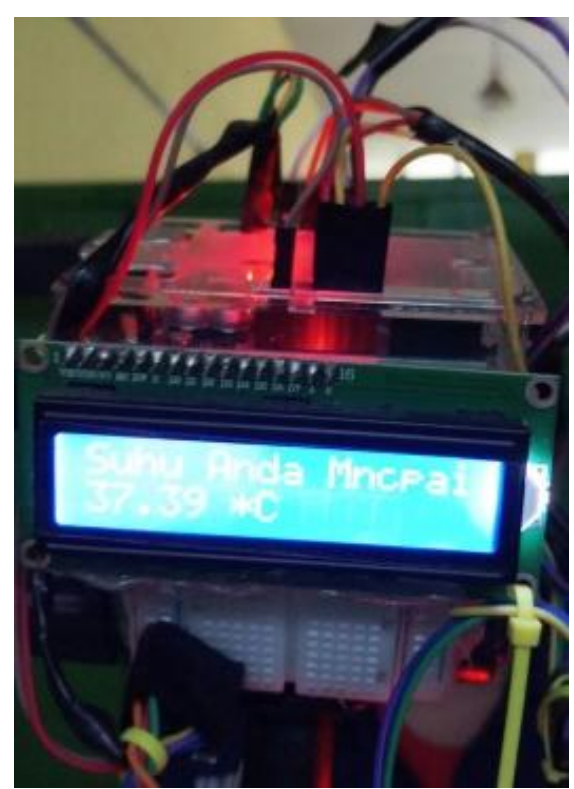

Figure 16. Temperature $>37^{0} \mathrm{C}$

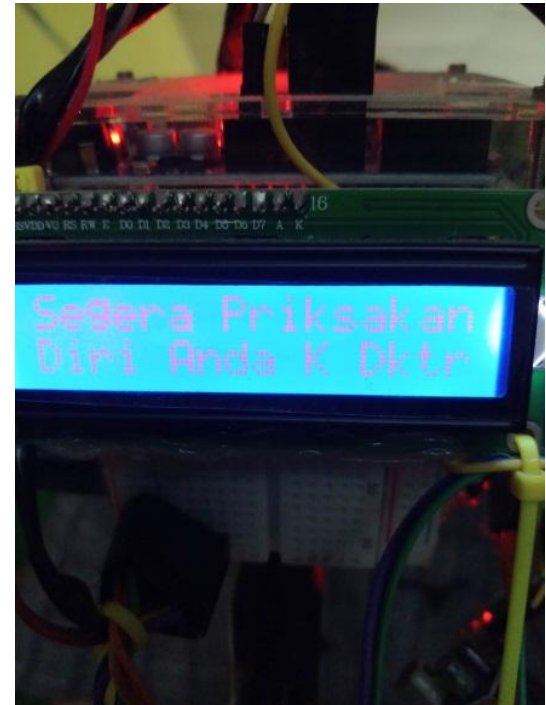

Figure 17. Check with the doctor

\section{CONCLUSION}

From the results of the tests carried out, it can be concluded that the Arduino Uno microcontroller can control the JSNSR04T water level sensor to measure the water level with the Led indicator on: Green Led full water, Yellow Led medium water, Red Led low water and Sensor MLX90614 to detect human temperature, where if the temperature is $\left\langle 37^{\circ} \mathrm{C}\right.$ the LCD display is normal temperature, but if the temperature is $>$ $=37^{0} \mathrm{C}$ the LCD display is checked by a doctor because there is a risk of contracting Covid 19.

\section{THANK-YOU NOTE}

The authors would like to thank P3M Politeknik Negeri Manado and all those who can not be mentioned one by one so that this research can be done.

\section{REFERENCES}

[1] Budhiharto, W.; Computer and Microcontroller Interfacing; Publisher Elex Media Komputindo, Jakarta. 2017.

[2] Brian W. Evans, Arduino Programming Notebook, creative Commons Attribution-Share Alike 2.5 License, 2018.

[3] Brilianti, F.D. Bukhari, I. and Sari, K.M., 2019, Prototype Automatic Hight Water Surface Detection in PDAM Water Reservoir Using Microcontroller-Based Ultrasonic Sensor, Smart Comp, Vol. 08 No. 1, pp. 3137.

[4] HerySuryantoro, Almira Budiyanto, Labview\& ArduinoBased Water Level Monitoring System Prototype as a Supporting Facility for Control System Instrumentation Practicum, Indonesian Journal of Laboratory Vol. 1(3) 2019, 20-32, ISSN 2655 4887, 26441624 (Online).

[5] Ines Monica Sari, NiniFirmawati, Design of an Automatic Water Level and Temperature Control System for Dairy Cattle Cages Based on Arduino Uno, Journal of Physics Unand (JFU), Vol. 9, No. 4, October 2020, 558564, ISSN : 2302-8491; 2686-2433 (Online).

[6] RausanFikri, Boni P. Lapanporo1 and Muh Ishak Jumarang, Design and Build a Water Level Monitoring System Using an ATMEGA328P Microcontroller Based 
on Web Service, POSITRON Vol. V. No.2 (2015), 4349, ISSN : 2301-4970

[7] Siswanto, Aditya Adiguna and WinduGata, Control and Monitoring of Aquarium Water Temperature and Altitude With Sensor DS18B20, HCSR04 and Arduino Uno R3 Microcontroller, Proceedings of the 9th SNST 2018 FK. Wahid Hasyim University, ISBN 978-60299334-9-9.
[8] Sasongko, Bagus Hari, Microcontroller Programming in C. Yogyakarta: Andi, 2012.

[9] Steven F. Barrett, Atmel AVR Microcontroller Programming And Interfacing, First Edition, Colorado (USA): Morgan and Claypool Publishers, 2017. 